Respiratory infections and asthma

David Isaacs and Preeti Joshi

THE RELATIONSHIP between asthma and respiratory infections is an important one, in two respects. Firstly, respiratory infections with viruses and allied organisms, such as Mycoplasma and Chlamydia species, are frequent causes of exacerbations of asthma, particularly in children, and are thus important triggers. Secondly, respiratory syncytial virus (RSV) infection and, more recently, Chlamydia infection have been proposed as possible causes of asthma.

\section{Viral infections and asthma}

Most exacerbations of asthma in childhood can be proven to be associated with viral infections. In a study by Johnston et $\mathrm{al}^{1}$ using the polymerase chain reaction (PCR) and culture, viruses were detected in $80 \%$ of episodes of wheeze or reduced peak flow in 9-11-year-olds with asthma. Rhinoviruses accounted for $61 \%$ of the viruses detected, coronaviruses $16 \%$, influenza $9 \%$, parainfluenza $9 \%$, and RSV $5 \%$.

Rhinoviruses have been detected in lower-airway cells during experimental rhinovirus infection. ${ }^{2}$ The mechanism by which viruses cause bronchospasm is not yet understood, but is likely to involve cytokine production in response to viral replication in the lower airway.

RSV infection, although detected in only $5 \%$ of asthma episodes in the study by Johnston et al, ${ }^{1}$ is known to be a potent cause of wheezing, particularly in infancy. It has been shown that RSV infections in infancy are associated with a $\mathrm{T}_{\mathrm{H}}$ 2-like cytokine response (see page $\mathrm{S} 66^{3}$ ) in the upper airway, whether or not the infant is atopic. ${ }^{4} \mathrm{~T}_{\mathrm{H}} 2$ cytokine patterns are known to be associated with viral immunopathology and allergic-type responses, in contrast to $\mathrm{T}_{\mathrm{H}} 1$ cytokine patterns, which are classically associated with viral elimination. It has also been shown that levels of at least one cytokine (IL-2) are similar in upper and lower respiratory tract secretions during RSV infection, suggesting that upper respiratory tract levels can be used as an indicator of lower respiratory tract levels. ${ }^{5}$ Interestingly, the nasal cytokine responses to rhinoviruses are of the $T_{H} 1$ type, ${ }^{4}$ as are the responses to other viruses (except RSV). This could explain the propensity for RSV to cause wheezing, but not the association between other respiratory viruses and wheezing.

Department of Immunology and Infectious Diseases, The Children's Hospital at Westmead, and University of Sydney, NSW.

David Isaacs, MD, FRACP, FRCPCH, Senior Staff Physician and Clinical Professor; Preeti Joshi, PhD, FRACP, Staff Physician. Correspondence: Professor David Isaacs, Department of Immunology and Infectious Diseases, The Children's Hospital at Westmead, Locked Bag 4001, Westmead, NSW 2145. davidi@chw.edu.au

\section{ABSTRACT}

\section{What we know}

- Respiratory viral infections caused by rhinoviruses, coronaviruses, influenza, parainfluenza and respiratory syncytial viruses (RSVs) are important triggers of asthma attacks.

- Mycoplasma and Chlamydia infections can also provoke asthma attacks, although less commonly.

- RSV infections probably do not cause asthma, but are potent triggers of wheezing, with the result that RSV infection often reveals underlying asthma in children.

- RSV infection does not cause atopy.

- Bacterial respiratory infections in infancy appear to protect against later atopy.

\section{What we need to know}

- Does RSV infection in infancy alter a child's $T_{H} 1 / T_{H} 2$ responses to later infections with other respiratory pathogens?

- What are the mechanisms (immunological or mechanical) by which respiratory pathogens cause wheezing?

- What is the role of respiratory infections in exacerbations of asthma? Can epidemiology shed light on this?

- Do viruses such as RSV cause asthma or uncover underlying asthma?

- Do children respond differently to RSV than to other viruses? Does atopy affect those responses?

- Do bacterial respiratory infections truly protect against future atopy?

\section{MJA 2002; 177: S50-S51}

\section{Does RSV infection cause asthma?}

There is controversy as to whether RSV infection in infancy can cause asthma, or merely uncovers pre-existing asthma. The evidence to date favours the latter. ${ }^{6,7}$ The incidence of later asthma is higher compared with controls for infants whose RSV bronchiolitis is severe enough to require hospitalisation, ${ }^{6,7}$ but not for infants who develop milder RSV bronchiolitis that can be managed at home. ${ }^{8} \mathrm{~A}$ recent study has suggested that RSV bronchiolitis in infancy is associated with an increased risk of recurrent wheeze up to six years of age, but that the risk decreases markedly after that age. ${ }^{9}$ No association was found between RSV lower respiratory tract infection and atopy.

\section{Chlamydia pneumoniae}

Chlamydia pneumoniae causes $5 \%-20 \%$ of communityacquired pneumonia in children and adults. ${ }^{10} \mathrm{C}$. pneumoniae 


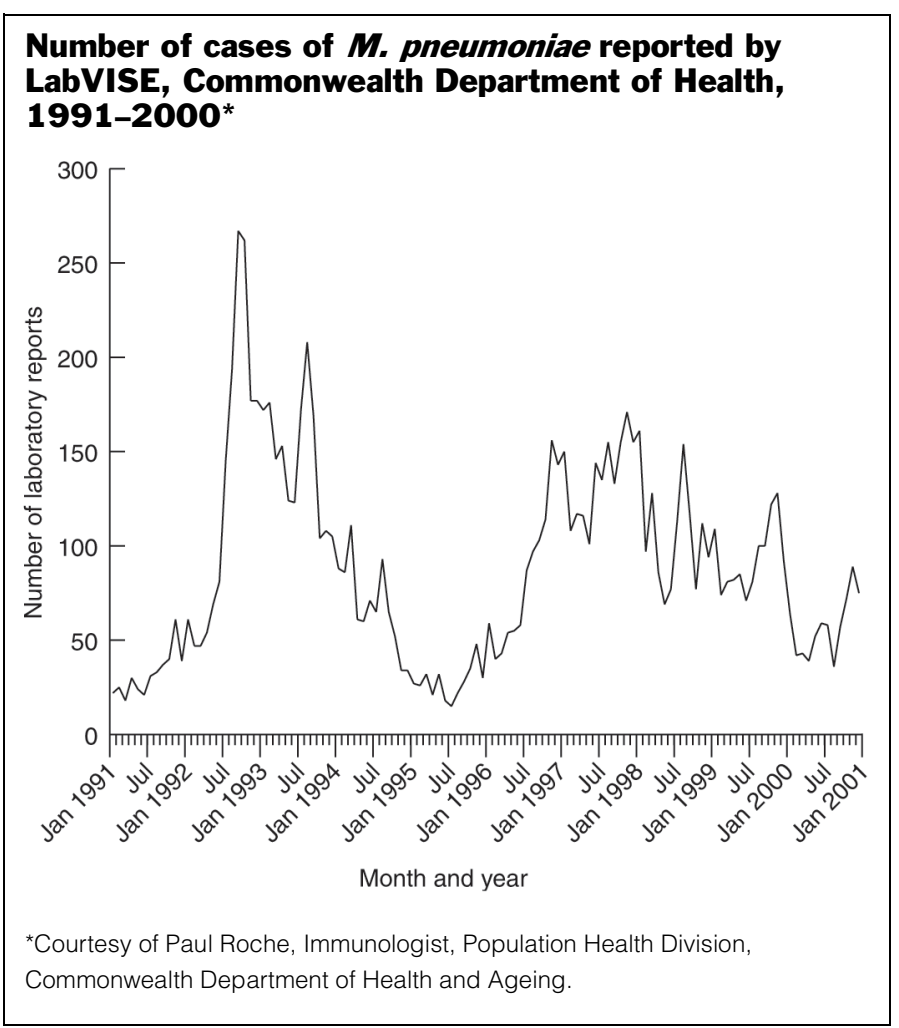

is not associated with asthma in children, but serological studies have suggested a possible association with new-onset asthma in adults and with chronic stable asthma. ${ }^{11}$ Serological studies in adults with asthma suggest a possible role for C. pneumoniae in the pathogenesis of severe asthma. ${ }^{11} \mathrm{~A}$ trial of roxithromycin in adults with asthma and serological evidence of recent Chlamydia infection showed only shortterm benefit, ${ }^{12}$ and this may have been due to the known anti-inflammatory effects of macrolides ${ }^{13}$ rather than to any antibacterial effect.

\section{Mycoplasma pneumoniae}

Mycoplasma pneumoniae classically causes dry cough and fever in school-aged children ( $\geqslant 5$ years old). ${ }^{14}$ Wheeze is not a classical symptom of Mycoplasma infection, although it may occur, and Mycoplasma is an uncommon cause of exacerbations of asthma. ${ }^{1,15} M$. pneumoniae occurs in outbreaks every three to five years, and is relatively uncommon between these epidemics (see Box ). ${ }^{14}$

The diagnosis of Mycoplasma infection is problematic. Culture is slow and insensitive. Serum $\operatorname{IgM}$ is a sensitive indicator of infection, but, because it persists for up to 12 months, is not specific. A single high complement fixation test (CFT) result, which detects IgG and IgM, has the same problem as IgM, while a rising CFT is specific but only $50 \%$ sensitive. The use of macrolide antibiotics should be reserved for children in whom there is a high suspicion of atypical pneumonia - they should certainly not be used routinely to treat acute asthma.

\section{Bacterial infections}

There is accumulating evidence that frequent respiratory infections in infancy, particularly bacterial infections, may protect against atopy. ${ }^{16}$ This may explain the low rate of atopic asthma in Indigenous children and adults found in one study, ${ }^{17}$ although recent data from Western Australia and Queensland suggest that asthma may be more common in Indigenous people than the earlier study reported.

\section{Conclusions}

It is known that some respiratory pathogens provoke asthma attacks, although much is still unknown about the mechanisms involved and why some pathogens are more potent inducers of wheeze than others. The possibility that organisms such as RSV and Chlamydia might actually cause asthma is intriguing but needs further study.

\section{References}

1. Johnston SL, Pattemore PK, Sanderson S, et al. Community study of role of viral exacerbations of asthma in 9-11 year old children. BMJ 1995; 310: 1225-1229.

2. Gern JE, Galagan DM, Jarjour NN, et al. Detection of rhinovirus RNA in lower airway cells during experimentally induced infection. Am J Respir Crit Care Med 1997; 155: 1159-1161.

3. Anderson GP. Therapeutic prospects for early asthma. Med J Aust 2002; 177 Suppl Sep 16: S66-S69.

4. Joshi P. A cohort study of cytokines and atopy [PhD thesis]. University of Sydney, 2001

5. Joshi P, Kakakios A, Jayasekera J, Isaacs D. A comparison of IL-2 levels in nasopharyngeal and endotracheal aspirates of babies with respiratory syncytial viral bronchiolitis. J Allergy Clin Immunol 1998; 102: 618-620.

6. Wang S-Z, Forsyth RD. Asthma and respiratory syncytial virus infection in infancy: is there a link? Clin Exp Allergy 1998; 28: 927-935.

7. Welliver RC. RSV and chronic asthma. Lancet 1995; 346: 789-790.

8. McConnochie KM, Roghmann KJ. Predicting clinically significant lower respiratory tract illness in childhood following mild bronchiolitis. Am J Dis Child 1985; 139: 625-631.

9. Stein RT, Sherrill D, Morgan WJ, et al. Respiratory syncytial virus in early life and risk of wheeze and allergy by age 13 years. Lancet 1999; 354: 541-545.

10. Hammerschlag MR. Chlamydia pneumoniae and the lung. Eur Respir J 2000; 16 : 1001-1007.

11. Johnston SL. Is Chlamydia pneumoniae important in asthma? The first controlled trial of therapy leaves the question unanswered. Am J Respir Crit Care Med 2001; 164: 513-514.

12. Black PN, Francesco B, Jenkins $R$, et al. Trial of roxithromycin in subjects with asthma and serological evidence of infection with Chlamydia pneumoniae. Am J Respir Crit Care Med 2001; 164: 536-541.

13. Amayasu H, Yoshida S, Ebana S, et al. Clarithromycin suppresses bronchial hyperresponsiveness associated with eosinophilic inflammation in patients with asthma. Ann Allergy Asthma Immunol 2000; 6: 594-598.

14. File TM Jr, Tan JS, Plouffe JF. The role of atypical pathogens: Mycoplasma pneumoniae, Chlamydia pneumoniae, and Legionella pneumophila in respiratory infection. Infect Dis Clin North Am 1998; 12: 569-592.

15. Micillo E, Bianco A, D'Auria D, et al. Respiratory infections and asthma. Allergy 2000; 55(Supp 61): 42-45

16. Von Mutius E, Illi S, Hirsch T, et al. Frequency of infections and risk of asthma, atopy and airway hyperresponsiveness in children. Eur Respir J 1999; 14: 4-11.

17. Peat JK, Veale A. Impact and aetiology of respiratory infections, asthma and airway disease in Australian Aborigines. J Paediatr Child Health 2001; 37: 108112 